\title{
THE CAFFEINE FOR APNEA OF PREMATURITY (CAP) TRIAL: PRELIMINARY OUTCOMES
} AT 5 YEARS

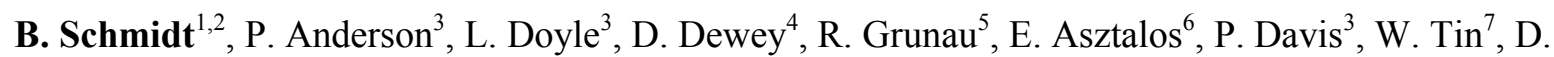
Moddemann $^{8}$, A. Solimano ${ }^{5}$, A. Ohlsson ${ }^{6}$, K. Barrington ${ }^{9}$, R. Roberts ${ }^{2}$, Caffeine for Apnea of Prematurity Trial Group

${ }^{1}$ University of Pennsylvania, Philadelphia, PA, USA, ${ }^{2}$ McMaster University, Hamilton, ON, Canada, ${ }^{3}$ University of Melbourne, Melbourne, VIC, Australia, ${ }^{4}$ University of Calgary, Calgary, AB, ${ }^{5}$ University of British Columbia, Vancouver, BC, ${ }^{6}$ University of Toronto, Toronto, ON, Canada, ${ }^{7}$ James Cook University, Middlesbrough, $U K,{ }^{8}$ University of Manitoba, Winnipeg, $M B,{ }^{9}$ University of Montreal, Montreal, $Q C$,

\section{Canada}

Background: The CAP trial enrolled 2006 infants with birth weights 500-1250 g who were randomly assigned to caffeine therapy or placebo for apnea of prematurity (N Engl J Med 2006; 354: 2112 and 2007; $357: 1893)$.

Objective: To reassess CAP trial participants at 5 years.

Design and methods: The main outcome at 5 years was a composite of death or survival with disability in one of 6 domains including neuromotor function, cognition, behaviour, and general health. Standardized tests included the Gross Motor Function Classification System (GMFCS), the Wechsler Preschool and Primary Scale of Intelligence, and the Child Behavior Checklist Parent Form.

Results: A total of 1932 children were eligible for the present study. Vital status was ascertained for 1810 children (94\%). Adequate data for the composite outcome of death or disability were available for 1641 children (85\%). Table 1 shows the results for the composite outcome and for 5 of its components.

\begin{tabular}{|l|l|l|l|}
\hline Outcome & Caffeine & Placebo & OR (95\% CI) \\
\hline Death or disability & $22 \%$ & $25 \%$ & $0.8(0.7-1.0)$ \\
\hline \hline Death & $6.4 \%$ & $6.5 \%$ & $1.0(0.7-1.4)$ \\
\hline \hline GMFCS level $>1$ & $2.4 \%$ & $3.8 \%$ & $0.6(0.4-1.1)$ \\
\hline Full Scale IQ $<70$ & $4.9 \%$ & $5.1 \%$ & $1.0(0.6-1.6)$ \\
\hline Disabling behaviour & $5.4 \%$ & $7.1 \%$ & $0.8(0.5-1.2)$ \\
\hline Health problem & $4.0 \%$ & $4.3 \%$ & $0.9(0.6-1.5)$ \\
\hline
\end{tabular}

[Table 1]

Conclusions: Observed rates of functional outcomes at 5 years still favoured caffeine therapy for apnea of prematurity over placebo treatment. However, cognitive impairment was no longer reduced in caffeinetreated infants. 